\title{
COVID-19 and Management of Parallel Disasters
}

\author{
Suresh Kumar Rathi ${ }^{1 *}$ and Soham Chakraborty ${ }^{2}$ \\ Indian institute of Public Health, Kavuri Hills, Madhapur, Hyderabad
}

\begin{abstract}
Corona virus has taken up the limelight in the sector of disasters since its arrival, however since then the world has faced various other major and minor hazards which have turned into disasters. Be it the Beirut explosion or the Air-India plane crash, disasters have been continuously creating trouble for people. Being in the same time as Covid-19, these disasters can be labelled as parallel disasters. Parallel disasters are difficult to manage as they have a cumulative impact. Sometimes there are multiple hazards and sometimes one hazard leads to another, both the times disaster management becomes very difficult. However, there is one field in the form of public health which can strengthen the resilience of the population and thus decrease the cumulative impact without even interacting directly with the disaster.

In this article, we look at various types of disaster, along with Covid-19, which have either caused havoc or have the potential to become catastrophes, in the Indian context. The article will look at natural disasters like floods, earthquakes, cyclones and the very devastating heat waves along with man-made disasters like industrial disasters and oil spills. The article will also give a considerable heed to epidemics in the form of Covid-19. We will touch upon the topic of disaster management for all the mentioned disasters which can act as parallel disasters in India and look at why public health can be an important element in management of parallel disasters. Finally the article will talk about the Indian disaster management policy and institutional framework and look at where and how parallel disasters and public health systems can be incorporated in it.
\end{abstract}

Keywords: Disaster $\cdot \operatorname{COVID}-19 \cdot$ Epidemics $\cdot$ Earthquake $\cdot$ Cyclone $\cdot$ Heat Wave $\cdot$ Policy

\section{Introduction}

\section{Parallel Disasters}

There are many disasters which have seriously affected the well-being of humankind since times immemorial. Be it the eruption of Mt. Vesuvius, the bubonic plague or the nuclear reactor explosion in Chernobyl, the world has been through innumerable catastrophes which has taken a heavy toll on its residents. People belonging to this generation, who were not familiar with massive epidemic disasters like the plague, smallpox or Spanish Flu, have now been introduced to the most recent global disaster, the Covid-19 pandemic. Corona virus has been the main subject of discussion since its inception in January, 2020 in India and it deserves every inch of the limelight it is getting. However, this has clearly overshadowed the other disasters which have occurred since then. The effect of the other disasters has also been a lot and Covid-19 has only worsened the cumulative impacts. This brings up the topic of parallel disasters, which certainly has a greater impact than one disaster at a time. Parallel disasters bring up the existing vulnerabilities within the population and impacts the ability to cope with any one particular disaster, thus having a profound effect altogether. The world, which is already in a very vulnerable state, is and further will be getting impacted by the parallel disasters. At the very basics, parallel disasters can arise out of multi-hazard scenarios and due to cascading effect of other disasters [1,2]. Multi-hazard scenarios include the instances where two or more hazards have presented itself at the same time; the most recent example would be the Amphan Cyclone in West Bengal happening in the midst of the global Covid-19 pandemic. Cascading effect of disasters can signify how one disaster leads to another hazard, which has the potential to become a disaster. This can include the 2020 Kerala floods and heavy rainfall which

*Address for Correspondence: Dr. Suresh Kumar Rathi, Indian institute of Public Health, Amar Co-operative Society, Kavuri Hills, Madhapur, Hyderabad, E-mail: rathisj07@gmail.com

Copyright: ๑) 2020 Rathi SK, et al. This is an open-access article distributed under the terms of the Creative Commons Attribution License, which permits unrestricted use, distribution, and reproduction in any medium, provided the original author and source are credited.

Received 03 September 2020; Accepted 15 September 2020; Published 22 September 2020 has directly resulted in landslides killing hundreds of people and an aircraft crash killing 18 [2-4].

While on the concept of parallel disasters, it can be useful to understand the concepts of disaster and disaster management and the types of disasters. A disaster can be defined as an outcome of an event (hazard) which have caused great amount of death and destruction. Risk is the probability of loss from such an event and vulnerability is the conditions which determine that probability. Coping capacity is the ability that reduces such vulnerabilities [5]. Disasters can be of three types which are anthropogenic (man-made like industrial and nuclear), natural (like earthquakes and cyclones) and epidemics (like covid-19) [6].

\section{Public Health and Disaster Management}

Management of parallel disasters and public health goes hand in hand. The relationship is more intertwined than it was previously thought. Public health in disaster management plays a very crucial role. On one hand, it empowers the general population by decreasing vulnerability and increasing coping capacity, enough to resist the impacts of a hazard. On the other hand, when the hazard or hazards have become a disaster, public health aims to bring down the casualties and prepare the population for the next such event. However, after the paradigm shift from response to mitigation based disaster management, the former goal of empowering the general population seems to be significantly more important [7]. The Covid-19 pandemic is again proving the same. A 2013 study had pointed out that $95 \%$ of the world's population is suffering from a health problem, and $33 \%$ have five or more health conditions together [8]. The most common are Asthma allergy, Blood pressure, Cancer, Diabetes and epilepsy. These are all responsible in increasing vulnerability and risk of individuals during parallel disaster situations. If the percentage of people with existing health issues (co-morbidities) can be brought down, the casualties of disasters will drop immediately. This explains the role of health and public health in disaster management [9]. The next section of the article will look at several disasters which can occur together or individually and can be catastrophic in nature. This will be followed by their management techniques and implications in national policy and legal framework.

\section{Heat Waves}

One natural disaster which has a prolonged impact especially on urban areas is heat waves. In 2003, the entire continent of Europe saw massive 
number of deaths (>70k) due to heat waves [10]. India faces heat waves almost every year and some years like 2003,2015 , etc. have caused havoc in terms of number of deaths across the country. Andhra Pradesh lost 1421 people in 2003 and Odisha lost 2042 people in 1998 due to heat waves $[11,12]$. The Ahmedabad heat wave saw an excess of $43 \%$ in all-cause mortality during the 2010 heat waves while Surat saw 157 excess deaths in the same time [13]. In 2020, heat wave or extreme heat had again affected the general population, this time the victims were migrant workers who were walking home during the lockdown situation. Heat waves can cause heat fatigue, rash, syncope, cramps, exhaustion and stroke with fatigue and rash being the most common symptoms. Heat waves can also have indirect effects like reduced productivity, work performance, increased accidents, and more stress on heart and lung [14]. While taking the case study of Surat, the 2005-14 decade has shown an increase of $25.65 \%$ in number of days with Heat Index over $41^{\circ} \mathrm{C}$ than the 1985 to 1994 decade, thus proving that the problem of heat wave is increasing at a fast rate. Heat index above $40^{\circ} \mathrm{C}$ have shown an increase of $18 \%$ in allcause mortality in Surat [15]. Therefore, during the time of Covid-19, when the mortality rate across states are already high, heat waves can further increase the number of deaths to an exponential amount.

\section{Floods}

Another parallel disaster which has always affected India is floods. There have been 24 major floods in Surat between 1914 and 2013, out of those 4 between 2003 and 2013, showing the increasing frequency. The 2006 flood caused 150 deaths in Surat and humongous amount of damages. Other major floods which have caused havoc in India are the 2015 Chennai floods, 2013 Uttarakhand floods and the Kerala floods of 2018 among others. Management of floods during Covid-19 is a mammoth task. Out of these, the 2013 Uttarakhand floods created cascading disasters in the form of landslides. While talking about 2020, the Kerala floods have caused massive deaths and damages. It has directly or indirectly contributed to more than 132 deaths in the state. The floods and heavy rains have indirectly caused the Air-India Flight 1334 crash which killed 18 people. The floods have also caused two huge landslides in Munnar and Rajamala killing 101 people $[3,4]$. The Kerala floods of 2020 , thus have proved to be a parallel disaster both in forms of being in a multi-hazard scenario and also cascading other disasters simultaneously.

\section{Cyclones}

One disaster which has already caused extensive damages during the Covid-19 situation in West Bengal is the cyclone Amphan. This has damaged 1.5 million houses in the state and completely damaged 5500 houses in the capital, Kolkata. The cyclone has also killed 98 people in Bengal and 4 people in Odisha [16]. Along with the massive environmental damages, especially in the Sundarban deltas, the cyclone has also affected several industries like electric power, telecommunication, fisheries, etc. amassing a total loss of around 13.2 billion US dollars in West Bengal alone [17]. This disaster, in the times of Covid-19, has led to delays in response and management. Disruption of supply routes, protests and social distancing norms drastically reduced the rate of recovery from the disaster.

\section{Earthquakes}

Earthquakes can be another form of natural disaster which, if occurs with a very high magnitude during Covid-19, can be very tough to handle. India already has a history with terrible earthquakes including the Latur earthquake of 1993 and Bhuj earthquake of 2001, the latter of which caused around 20k deaths in Gujarat [18]. India has been affected again, however in a much smaller capacity, by earthquakes during the 2020 Covid-19 pandemic. There were three distinct earthquakes in Uttarakhand, Mizoram and Andamans causing damages to buildings. There also have been many minor earthquakes in Delhi-NCR, West Bengal and other states during this time, but none of them did significant damages [19]. However, given the current scenario, an earthquake of higher magnitudes can cause huge number of deaths in the country, and the public health and disaster management systems which has already been shackled by Covid-19 responsibilities might not be able to handle the task of quick response and recovery.

\section{Industrial disasters (Man-made)}

While these were few natural disasters, the world has also been scarred by various man-made disasters in the past and present, many of them remarkably during the Covid-19 era. The past ones include the Bhopal Gas Tragedy of 1984 which caused thousands of deaths and whose impacts are still visible in Bhopal [20]. Currently, in the international theatre, the Beirut blast has caused atleast 181 deaths and has left 300,000 people homeless [21]. India has also been impacted by such industrial accidents in the Covid era. The Vizag LG chemical plant gas leak is a prime example of this. It has caused more than 10 deaths and thousands of injuries [22].

Many man-made disasters also have the capacity to create a permanent damage on the environment and eco-system. The Chernobyl nuclear disaster has created a situation so radioactive, that it will take more than 20,000 years for the area to be radiation free. Similarly, there are disasters like Deep water horizon oil-spill, Exxon Valdez spill and the 2010 Coast of Mumbai oil spill which leads to damage in the marine ecosystem. The year 2020 also saw a major international oil spill in Mauritius. Similar incidents can also happen in India now that the shipping industry has slowed down maintenance due to Covid-19.

\section{Pandemics/Epidemics}

Epidemics are probably the most unique kind of disasters that can have a more wide-spread impact than all the other mentioned disasters. Some new and resurgent infections with epidemic potentials are Covid-19, H1N1, plague, Leptospirosis, Malaria, TB, Filaria, Dengue, etc. Out of these, Covid-19 has achieved pandemic status most recently and has already caused around 1 million deaths worldwide. Covid-19 is caused by the Novel Coronavirus and can cause even a healthy person to develop symptoms, have the symptoms become severe and die. The disease has several common and severe symptoms, the commons include fever, loss of smell, coughs, shortness of breath, etc. and the severe symptoms include difficulty in walking, confusion, very high fever, kidney failure, etc [23]. There can be four types of clinical classification of the disease including mild, moderate, severe and critical with the critical ones facing respiratory failure, septic shock and multi-organ failure. Healthcare workers including doctors, nurses, etc. are very much at risk due to this virus. The case of Bhilwara, Rajasthan proves the same thing.

\section{Management of Disasters and Parallel disasters}

Any form of disaster management involves four major stages which are mitigation, preparedness, response and recovery [24]. Disaster management should always involve the smallest representatives from villages, cities to the biggest representatives of the central government in order to have a holistic effect. There should also be a multisectoral approach with proper planning and inputs from the grass root levels. The plans should be different for different disasters and should be area specific. Discrimination should also be avoided at all costs in disaster management. The way to deal with parallel and cascading disasters is by taking a multi-hazard multi-sectorial approach, proper financing, training of disaster managers at every level, supply chain management and warehousing and moving to building resilience of population and infrastructure. Several tools like hazard risk vulnerability assessment, post disaster needs assessment, and etc. can be used for this purpose. Public health should also be a key focus during disaster management as this builds capacities and resilience of individuals and increases their capability to deal with a disaster or parallel disasters. Every plan for parallel disasters should be much focused and probably at city/ town or village level to have the maximum impact.

Looking at the management of all the above mentioned disasters and parallel disasters, there can be only one way to survive, which is to adapt to the circumstances. The only thing which Human Beings can do 
far better than other species is to innovate and disaster managers have to put that innovation to good effect. For heat waves there can be heat action plans which should be location specific and which should aid to early warning systems. One such example is the Ahmedabad Heat Action Plan which was formulated after the 2010 Ahmedabad heat wave [25]. Public awareness should also be raised and cooling centres should be created in public places. These cooling centres should be accessible to every section of the society in need and should be spread across the city for better effect. At individual level, people should try to reduce heat sources, at corporation level timely alerts can be sent out and at state/national level, capacity building measures can be taken. Public health systems can be used for better treatment of victims and can also aim at treating co-morbidities before the disaster strikes.

Floods and cyclones are disasters which can be predicted from beforehand. But what matters is the level of preparation after the warning and the management after the hazard has occurred. The best way to act before a cyclone or a flood is to create microzonations across the city or village. This allows for locale specific intervention during the disaster. This also helps in identifying safe places in the city where temporary shelters and camps can be set up during the evacuation phase. The state also has to be prepared with various forces which can help in disaster management like fire-brigades, police, etc.

For earthquakes, predicting and preventing is near to impossible, the destruction from earthquakes can be limited by implementing strict building codes, raising awareness and embracing new technologies to create city/ town based microzonations. Earthquake microzonation done in the city of Kolkata by IIT Kharagpur and Ministry of Earth Sciences can be a good example [26]. Technologies can be also used to deploy advanced robotics for search and rescue. Early warning systems could be used to predict and warn people about cascading effects like tsunamis and landslides.

Industrial disasters can be prevented at the start. Unlike natural disasters, man-made disasters can be nipped in the bud by following strict protocols and taking required safety measures. The industrial disasters like Vizag Gas Leak 2020 or Beirut explosion 2020 can be avoided with proper safety mechanisms and protocols at the major industrial hubs. Creation of buffer zones and green zones can also be a way of manage the damages if the hazard takes place. Disaster management teams should also be present and prepared at all times to avoid such catastrophes. Much like the industrial disasters, the other man-made disasters like oil-spills or major accidents can be prevented by making strict guidelines and protocol.

For Covid-19, the most demanding disaster right now, strict PPE's should be used by every individual. Health workers should be very particular about the use of PPE's. PPE protocols should be followed strictly at all times, including while wearing, while using and while removing and disposing. Along with PPE's, proper hygiene and social distancing protocols should also be maintained. City specific surveillance systems using mobile operated applications should also be used to keep track of the diseases. While this is true for Covid-19 right now, these measures can be taken for other epidemic too, with required variations. It should also be seen that the PPE wastes do not affect the environment in anyway and they should be disposed properly, otherwise they can lead to more parallel or cascading disasters. The WUHAN method is comprehensively the best method to stay away from Covid-19. This method includes washing hands with soaps, using masks, health and hygiene maintenance, avoiding hand to mouth and nose and no group gathering. The method is the acronym generated from the first letter of each of the steps and is ironically named after the city which holds the epicentre of Covid-19.

\section{Policy Implications}

The previous segment talks about various methods which can be used to manage parallel disasters. It has also explained how public health can be integrated into disaster management to get a better outcome. However, to have a more comprehensive approach towards disaster management, there needs to be proper policy and legal frameworks. The Indian disaster management policy framework is based upon the National Disaster Management Policy, 2009. This policy has clearly described the legal and institutional framework for disaster management in India involving the National DM Act of 2005, the several bodies like National Disaster Management Authority, State authorities, National Disaster Response Force, National Institute of Disaster Management, etc $[27,28]$. The whole set-up has several instrumental points in tackling disaster, however, it doesn't acknowledge the role of integrated public health in the institutional framework. The National Disaster Management Plan, which is very comprehensive, looks at multi-hazard scenarios in particular, but fails to acknowledge heat waves as a major natural hazard. It also doesn't focus on epidemic management, which in 2020 (Covid-19 Pandemic) is the need of the hour [29]. Therefore, the first most essential thing which has to be done to manage parallel disasters, both individually and as a whole (through capacity building), is to include a wide range of multi-hazard scenarios and cascading effects in the National policies, plans and frameworks. Public Health should also be introduced into the institutional framework of the Indian disaster management system which will definitely help in capacity building of the population, thereby reducing risk. The involvement of parallel disasters and public health systems should not be limited to the national level plans and policies but should reach the deepest level of the community through state level, city/town/village level disaster management plans.

\section{Conclusion}

Public health is one angle which is regularly given less credits in calamity and disaster management. The Covid-19 pandemic has shown us the importance of strong public health systems. In case of disasters which are occurring at parallel with Covid-19, it is very essential to include public health comprehensively into the disaster management systems. While the paradigm of disaster management has shifted from a post-disaster response based to a pre-disaster capacity building form, public health still hasn't been able to make its way into most disaster management plans. The need of the hour is to make the population as resilient as possible. It is possible to manage the Parallel disasters with various management techniques, however when the disasters start occurring together, then its only up to the resilience of the people and the society that can withstand the disasters. Thus, along with the disaster management procedures, it is also critical to focus upon a solid public health system to get rid of the vulnerabilities to parallel threats and ultimately reduce disaster risk. The involvement of planning at every stage of disaster management from National to the grass root level should involve public health and the management of parallel disasters. After the successful incorporation of all the mentioned features into disaster management policies, plans and frameworks, India can be able to fight against parallel disasters even during tough times like the Covid-19 pandemic.

\section{References}

1. David, Alexander and Gianluca Pescaroli. "A definition of cascading disasters and cascading effects: Going beyond the "toppling dominos" metaphor." Planet@Risk 3(2019):58-67.

2. Gill, Joel $C$ and Bruce Malamud D. "Reviewing and visualizing the interactions of natural hazards." Rev. Geophys 52(2014):680-722.

3. "Kerala plane crash: 18 dead after Air India plane breaks in two at Calicut." BBC News, August 07, 2020.

4. "India landslide: Dozens feared dead after flooding in Kerala." BBC News, August 08, 2020.

5. "Understanding Disasters." National Institute of Disaster Management

6. Shaluf, Ibrahim Mohamed. "An overview on disasters." Disaster Prev Manag 16(2007):687-703. 
7. "Disaster Risk Management for Health." Disaster Risk Management for Health Fact Sheets. World Health Organisation, 2011.

8. "Global Burden of Disease Study 2013 Collaborators. Global, regional, and national incidence, prevalence, and years lived with disability for 301 acute and chronic diseases and injuries in 188 countries, 1990-2013: A systematic analysis for the Global Burden of Disease Study 2013." The Lancet 386(2015);(9995):743-800.

9. Khan, Yasmin, Tracey O'Sullivan, Adalsteinn Brown and Shannon Tracey, et al. "Public health emergency preparedness: a framework to promote resilience." BMC Public Health 18(2018):1-16.

10. Robinea, Jean Marie, Siu Lan K Cheunga, Sophie Le Roy and Herman Van Oye, et al. "Death toll exceeded 70,000 in Europe during the summer of 2003." C R Biologies 331(2008):171-178.

11. De, US, and Mukhopadhyay RK. "Severe heat wave over the Indian subcontinent in 1998, in perspective of global climate." Curr Sci 75(1998):1308-1311.

12. Suchitra, M. "Heat wave death toll nears 2,000 in Andhra, Telangana." Down To Earth, September 17, 2015.

13. Desai, Vikas K, Shailesh Wagle, Suresh Kumar Rathi and Urvi Patel, et al. "Effect of ambient heat on all- cause mortality in Surat City." Curr Sci 109(2015):1680-1686.

14. Zuoa, Jian, Stephen Pullen, Jasmine Palmer and Helen Bennetts, et al. "Impacts of heat waves and corresponding measures: a review." J Clean Prod 92(2015):1-12.

15. Desai, Vikas K, Urvi Patel, Suresh K Rathi and Shailesh Wagle, et al. "Temperature and Humidity Variability for Surat (coastal) city, India." Int J Environ Sci 5(2015):935-946.

16. "Death toll due to cyclone 'Amphan' in West Bengal now 98: Mamata Banerjee." PTI, The Times of India, May 29, 2020.

17. Sud, edika, and Prema Rajaram.. "Cyclone Amphan caused an estimated
\$13.2 billion in damage in India's West Bengal: government source." Weather, May 22, 2020.

18. "Preliminary Earthquake Report." USGS Earthquake Hazards Program, Nov 20, 2007.

19. "Latest Earthquakes." USGS.

20. MP Government report.

21. Regencia, Ted, Linah Alsaafin and Ramy Allahoum. "Endemic corruption caused Beirut blast, says Diab: Live updates." LEBANON Aug 11, 2020.

22. Andhra Pradesh Bureau. "Visakhapatnam gas leak | Updates." The Hindu, May 07, 2020.

23. "Coronavirus." World Health Organisation, 2020.

24. Poser, Kathrin. "Volunteered Geographic Information for Disaster Management with Application to Rapid Flood Damage Estimation." Geomatica 64(2010):89-98.

25. "Ahmedabad Heat Wave Action Plan." Guide to Extreme Heat Planning in Ahmedabad, India, 2016.

26. Nath, SK. "Seismic Hazard, Vulnerability and Risk Microzonation Atlas of Kolkata." Ministry of Earth Sciences, IIT Kharagpur, India.

27. "Covid-19." National Disaster Management Policy, National Disaster Management Authority, India, 2019.

28. "National Disaster Management Act, 2005." National Disaster Management Authority.

29. "National Disaster Management Plan." National Disaster Management Authority, India, 2016.

How to cite this article: Suresh Kumar Rathi and Soham Chakraborty. "COVID-19 and Management of Parallel Disasters". Clin Infect Dis 4 (2020) doi: $10.37421 /$ jid.2020.4.128 